\title{
Coordination and Precipitation of Calcium Oxalate: Computation to Kinetics.
}

\author{
Supporting Information for Publication
}

Sean J. O’Kennedy*, Leané D. van Zijl, Charles van Rooyen, Luca Bertossi, Tatenda Blessing Shekede, Julia Joos-Vandewalle, Shane Smith, Anthony Turton

Nanodyn Systems Pty. Ltd., De Wagenweg Office Park Block C, Stellentia Road, Stellenbosch, 7600, Western Cape, South Africa. 
Contents:

Table SI 1 Operating concentrations for the experimental precipitation reactions in the Titrando Autotitrator

Figure SI 1 Powder X-Ray diffraction (PXRD) diffractogram of our experimental precipitate gained during the kinetics experiments compared to Whewellite's PXRD spectrum from RRUFF.info ${ }^{52}$. 
Table SI 1 Operating concentrations for the experimental precipitation reactions in the Titrando Autotitrator

\begin{tabular}{|c|l|l|}
\hline NO. & Temperature $\left({ }^{\circ} \mathrm{C}\right)$ & {$\left[\mathrm{Ca}^{2+}\right]$ and $\left[\mathrm{C}_{\mathbf{2}} \mathrm{O}_{\mathbf{4}}{ }^{2-}\right](\mathbf{m M})$} \\
\hline $\mathbf{1}$ & 30 & 10 \\
\hline $\mathbf{2}$ & 40 & 10 \\
\hline $\mathbf{3}$ & 50 & 10 \\
\hline $\mathbf{4}$ & 30 & 8.4 \\
\hline $\mathbf{5}$ & 40 & 8.4 \\
\hline $\mathbf{6}$ & 50 & 8.4 \\
\hline $\mathbf{7}$ & 30 & 7.5 \\
\hline $\mathbf{8}$ & 40 & 7.5 \\
\hline $\mathbf{9}$ & 50 & 7.5 \\
\hline
\end{tabular}


To corroborate and validate our results, a set of analyses were done to determine the chemical composition and morphology of the precipitate. Powder X-ray diffraction (PXRD) results indicate that the sample formed is pure whewellite (COM) as is expected from other studies.

Figure SI 1 shows that the PXRD peaks correspond exactly to a pure sample of whewellite. No weddellite or caoxite was present in the product. The sample was prepared directly from the reaction mixture by Buchner filtration and drying at $40^{\circ} \mathrm{C}$ for 2 hours.

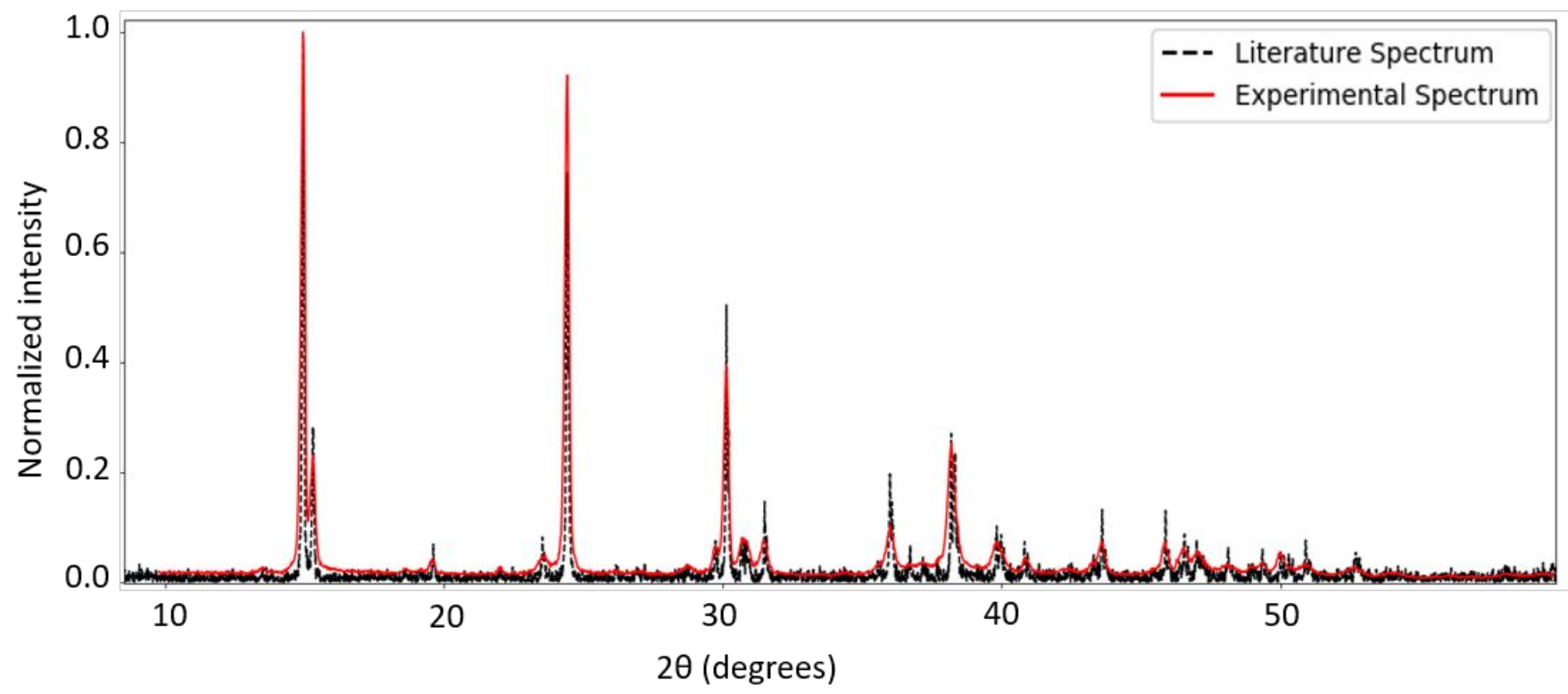

Figure SI 1 Powder X-Ray diffraction (PXRD) diffractogram of our experimental precipitate gained during the kinetics experiments compared to Whewellite's PXRD spectrum from RRUFF.info ${ }^{52}$. 
